\title{
PETA KOMPETENSI PROFESI OPERATOR MESIN PRODUKSI DAN GAP KOMPETENSI ANTARA KOMPETENSI LULUSAN SMK JURUSAN TEKNIK PEMESINAN DENGAN TUNTUTAN DUNIA KERJA (Studi kasus pada Bengkel Pemesinan di Kota Surakarta)
}

\author{
Herman Saputro, Bambang Pr., C. Sudibyo \\ Prodi Pendidikan Teknik Mesin, Jurusan Pendidikan Teknik dan Kejuruan, FKIP, UNS \\ Kampus UNS Pabelan Jl. Ahmad Yani 200, Surakarta, Telp/Fax 0271718419 \\ E-mail : bambangpr27@yahoo.com
}

\begin{abstract}
This research purpose is to explore extensively about the competencies required in the workplace, especially in profession of machine operators. The research also aims to find the gap that exists between the competence of vocational school graduates majoring in machinery with the demands of competence in the workplace. The research method used in this study is exploratory qualitative research method. From this research it can be seen that the macro level profession competence of machine operators can be classified into 3 groups of competencies, that is: 1) base competency, 2) Core Competency, and 3) supporting competency. Based on the base competency map, there was a gap between vocational school graduates with professional competence of machine operators, that is 1) competency to read engineering drawings and 2) competency using hand tools. Based on core competency map, $33 \%$ of vocational school graduates on levels less capable to work in core area of the machine operator profesion. Based on supporting-competency map, workshop-leaders and senior machine operators have assessed the ability of vocational school graduates are also less capable to perform the service to consumers.
\end{abstract}

Keywords: competence in the workplace and competence gap

\section{PENDAHULUAN}

Pendidikan kejuruan adalah bagian dari sistem pendidikan yang mempersiapkan seseorang agar lebih mampu bekerja pada satu bidang pekerjaan seperti bidang otomotif, industri, pertanian, perkantoran dll. Menurut Undang-undang No. 20 tentang Sistem Pendidikan Nasional, pasal 15 menyatakan: "Pendidikan Kejuruan merupakan pendidikan yang mempersiapkan peserta didik untuk dapat bekerja dalam bidang tertentu".

Sekolah Menengah Kejuruan (SMK) sebagai lembaga yang mempersiapkan lulusan siap kerja justru sebaliknya. Angka pengangguran tertinggi berdasarkan pendidikan didominasi oleh lulusan SMK. Di Indonesia, berdasarkan Badan Pusat Statistik atau BPS yang dikemukakan Kuswari (2009 : 1) bahwa : "Pengangguran terbuka didominasi lulusan SMK sebesar $17,26 \%$, SMA $14,31 \%$, Perguruan Tinggi $12,59 \%$, diploma $11,21 \%$, lulusan SMP $9,39 \%$, dan lulusan SD 4,57 \% dari jumlah penganggur".Melihat dari fenomena ini, terdapat beberapa faktor yang menyebabkan hal tersebut terjadi, diantaranya adalah kompetensi lulusan SMK yang belum relevan dengan kebutuhan dunia kerja atau dunia industri.

JIPTEK, Vol. VI No.1, Januari 2013
Permasalahan yang sedang dihadapi oleh SMK di Surakarta, diantaranya masalah tentang belum adanya kesesuaian antara kompetensi yang diharapkan dunia kerja terhadap lulusan Sekolah. Contohnya adalah belum dapat diterimanya lulusan jurusan Mekanik Otomotif di beberapa bengkel resmi di Surakarta dengan alasan kompetensi yang dimiliki belum cukup. Beberapa siswa SMK juga ditolak untuk melakukan Praktek Kerja Industri (Prakerin) di bengkel permesinan hanya gara-gara belum mampu mengoperasikan mesin CNC (Computer Numerical Control).

Bertolak dari permasalahan pembelajaran (kompetensi) dalam pendidikan kejuruan dan besarnya pengangguran lulusan smk, maka perlu dilakukan penelitian tentang "Peta Kompetensi Profesi Operator Mesin Produksi Dan Gap Kompetensi Antara Kompetensi Lulusan Smk Jurusan Teknik Pemesinan Dengan Tuntutan Dunia Kerja”.

\section{METODE PENELITIAN}

Penelitian ini menggunakan metode kualitatif dengan desain eksploratif survei. Penggunaan desain survei eksploratif dimaksudkan sebagai suatu upaya dalam pemecahan masalah dengan jalan mencari, 
menemukan dan mengatasi atau mencari solusi, membangun ide-ide atau hubungan-hubungan baru melalui fenomena atau peristiwa-peristiwa yang terjadi di masyarakat atau daerah, berdasarkan fakta di lapangan. Masalah yang ingin dicari jawabannya adalah mengenai kompetensi yang harus dimiliki oleh profesi operator mesin produksi. Sehingga alur penelitian pada penelitian ini dibaut seperti pada Gambar1 dibawah ini.

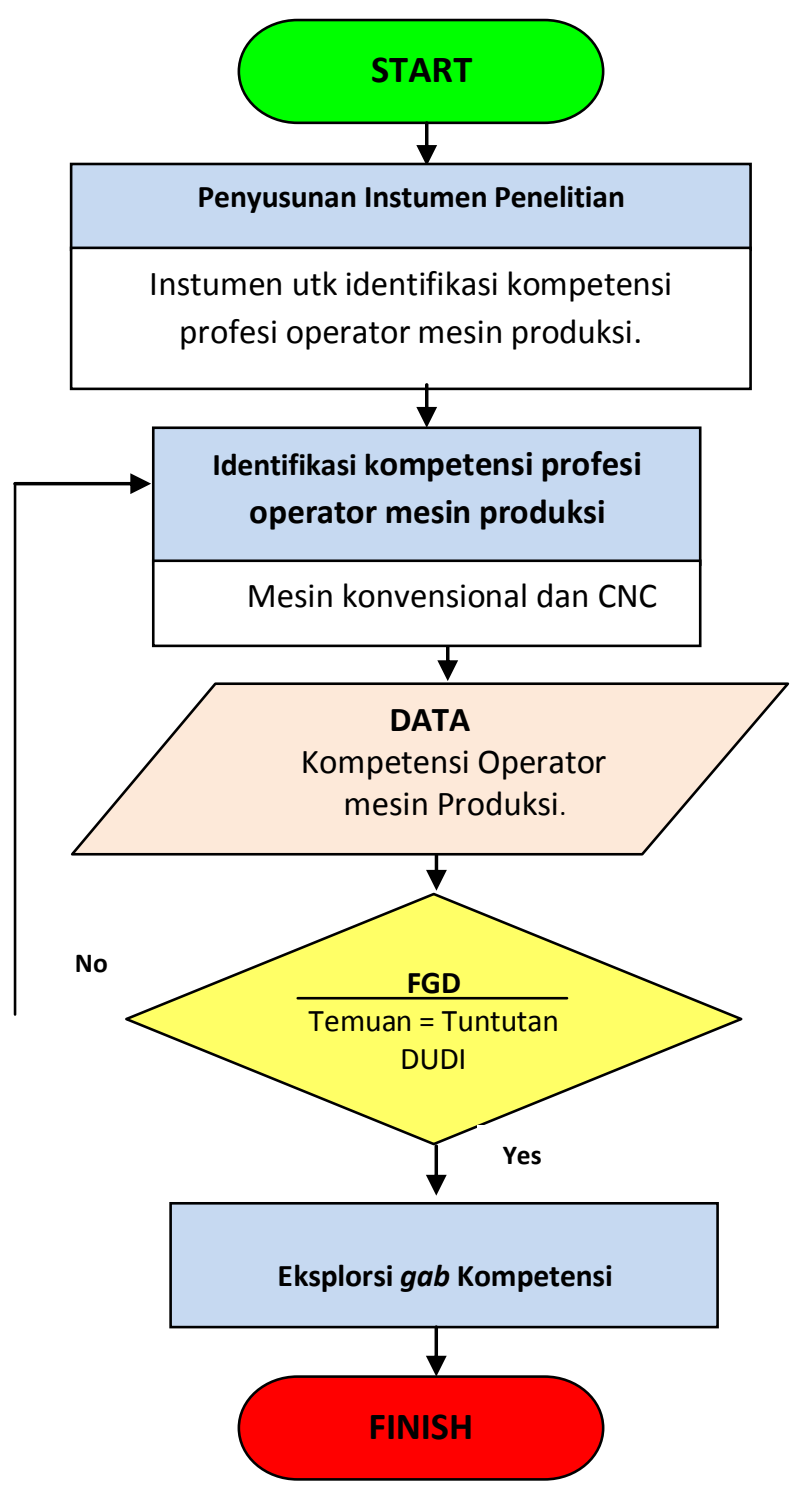

Gambar 1 Diagram alir penelitian

\section{HASIL DAN PEMBAHASAN}

Dari hasil penelitian yang telah dilakukan di bengkel pemesinan yang ada di Surakarta, yaitu: PT. King Manufacture, PT. Sinar Agung Selalu Sukses (SAS), PT. Success Plasindo, dan CV. Rigen Sarana Mukti didapatkan data kompetensi-kompetensi yang dituntut untuk menjadi seorang operator mesin produksi yang ideal. Dari data - data tersebut kemudian dibuat perumusan tentang pengelompokkan kompetensi-kompetensi yang sejenis atau serumpun. Berdasarkan masukan dalam forum group dikusi (FGD) dengan praktisi dibidang pemesinan dan dunia pendidikan, kompetensi-kompetensi tersebut dapat dikelompokkan kedalam 3 kelompok kompetensi yaitu: 1). Kompetensi dasar (Base Competency) operator mesin produksi, 2). Kompetensi inti (Core Competency) operator mesin produksi dan 3). Kompetensi penunjang (Supporting Competency) operator mesin produksi.

Kompetensi dasar (base competency) operator mesin produksi yaitu kombinasi keterampilan, pengetahuan dan kecakapan dalam menangani dan memahami materi dan proses berbagai obyek yang terkait dengan pekerjaan permesinan. Kompetensi ini melengkapi komptensi inti yang dipersyaratkan profesi operator mesin produksi. Keberadaan kompetensi dasar pada diri seorang operator mesin produksi merupakan syarat awal untuk menjadi seorang operator mesin produksi.

Kompetensi inti (Core Competency) operator mesin produksi yaitu kombinasi keterampilan, pengetahuan dan kecakapan yang dibutuhkan agar mampu melaksanakan tugastugas profesi operator mesin produksi secara minimal dengan kesalahan minimum. Kompetensi ini merujuk pada sejumlah pengetahuan dasar yang dibutuhkan dalam jabatan-jabatan operator mesin produksi yang spesifik.

Kompetensi penunjang (supporting competency) yaitu merupakan kombinasi keterampilan, pengetahuan dan kecakapan dalam hal mental dan sikap (thinking \& attitude), ekspresi kualitas personal (personal quality) dan kecakapan bekerja sama dengan orang lain (working with others) sehingga seorang operator mesin produksi memiliki kecakapan dalam memberikan impresi lebih pada profesinya.

\section{Kompetensi dasar (base competency operator mesin produksi}


Kompetensi dasar (base competency) yaitu kompetensi yang berhubungan dan menunjang dengan kompensi inti. Keberadaan kompetensi dasar pada diri seorang operator mesin produksi merupakan syarat awal untuk menjadi seorang operator mesin produksi. Kompetensi dasar operator mesin produksi adalah sebagai berikut Tabel 1 dibawah ini:

Tabel 1 Kompetensi Dasar profesi operator mesin produksi

\begin{tabular}{|l|l|l|}
\hline No. & \multicolumn{1}{|c|}{$\begin{array}{c}\text { Unit } \\
\text { Kompetensi }\end{array}$} & \multicolumn{1}{|c|}{ Penjelasan } \\
\hline 1 & $\begin{array}{l}\text { Memahami } \\
\text { tentang } \\
\text { material teknik }\end{array}$ & $\begin{array}{l}\text { 1. } \text { Menjelaskan jenis } \\
\text { meterial logam. } \\
\text { 2. Memahami kekerasan } \\
\text { dan kekuatan meterial } \\
\text { 3. Mampu memilih jenis } \\
\text { pahat berdasarkan } \\
\text { jenis meterial yang } \\
\text { akan dikerjakan. }\end{array}$ \\
\hline 2 & $\begin{array}{l}\text { Menggunakan } \\
\text { alat ukur }\end{array}$ & $\begin{array}{l}\text { 1. Mengukur dengan } \\
\text { alat mekanik presisi }\end{array}$ \\
& $\begin{array}{l}\text { 2. Mampu } \\
\text { menggunakan alat- }\end{array}$ \\
\hline
\end{tabular}

\begin{tabular}{|l|l|l|}
\hline & & \multicolumn{1}{|c|}{$\begin{array}{l}\text { alat ukur pneumatik } \\
\text { 3. Memelihara alat ukur }\end{array}$} \\
\hline 3 & $\begin{array}{l}\text { Menggunakan } \\
\text { perkakas } \\
\text { tangan } \\
\text { mekanik }\end{array}$ & $\begin{array}{l}\text { 1. Menggunakan } \\
\text { macam-macam } \\
\text { perkakas tangan } \\
\text { 2. Menggunakan } \\
\text { macam-macam } \\
\text { perkakas bertenaga }\end{array}$ \\
\hline 4 & $\begin{array}{l}\text { Membaca } \\
\text { gambar teknik }\end{array}$ & $\begin{array}{l}\text { 1. Menginterpretasikan } \\
\text { sketsa dan mampu } \\
\text { membuat sketsa }\end{array}$ \\
& $\begin{array}{l}\text { 2. Mendeskripsikan } \\
\text { gambar teknik } \\
\text { Memahami simbol- } \\
\text { simbol pengerjaan }\end{array}$ \\
\hline
\end{tabular}

Dari hasil wawancara dan diskusi bersama pimpinan bengkel, pimpinan mekanik dan operator mesin produksi senior serta angket yang disebarkan kepada 30 responden di 3 bengkel pemesinan, dapat diketahu gap kompetensi dasar operator mesin produksi dengan kompetensi yang dimiliki oleh lulusan SMK jurusan Teknik Pemesinan. Hasil diskusi dan kuesioner dapat disajaikan seperti pada Gambar 2 berikut ini:

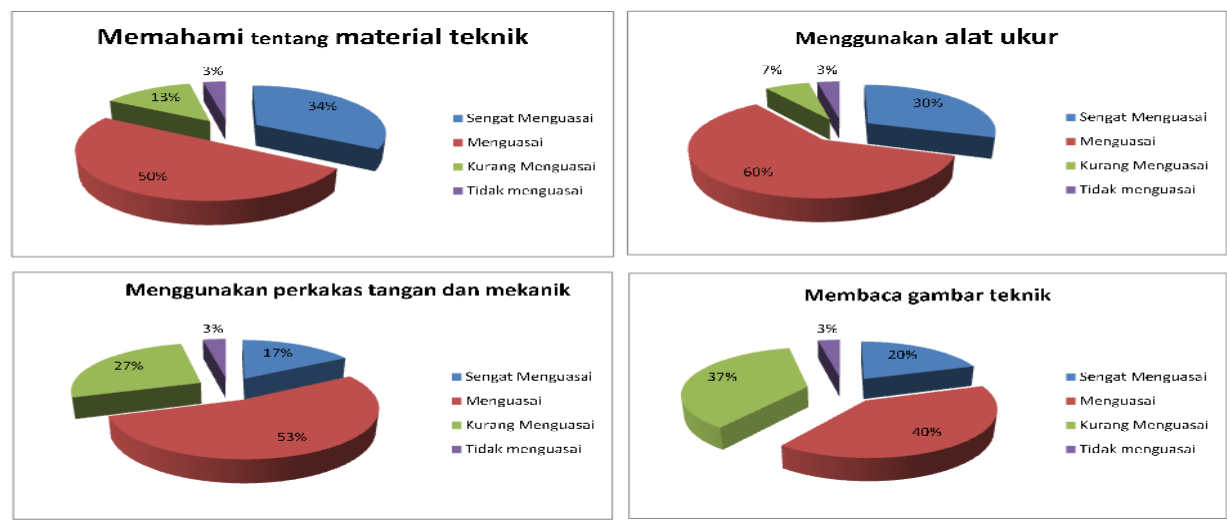

Gambar 2. Grafik penguasaan kompetensi dasar profesi operator mesin produksi lulusan SMK Jurusan Teknik Pemesinan

Dari hasil penelitian pada Gambar 2 dapat diketahui bahwa pada kompetensi dasar $g a b$ yang paling besar antara kompetensi lulusan dengan permintaan bengkel produksi adalah pada 1) kompetensi membaca gambar teknik dan 2) kompetensi menggunakan perkakas tangan. Dari hasil wawancara dengan narasumber kebanyakan siswa yang baru lulus dari SMK kurang bisa dalam membaca gambar teknik, khususnya simbul-simbul pengerjaan. Padahal dalam pemesinan simbul pengerjaan sangatlah penting. Selain gambar simbol pengerjaan tenaga baru lulusan SMK bisanya lemah dalam membuat sket gambar dan membaca sket gambar.

\section{Kompetensi inti (Core Competency)}

Kompetensi inti yaitu kompetensi utama yang berkaitan dengan profesi operator mesin produksi. Dalam penelusuran yang dilakukan untuk profesi operator mesin produksi dapat dikelompokkan seperti Tabel 2 berikut ini: 
Tabel 2 Kompetensi inti profesi operator mesin produksi

\begin{tabular}{|c|c|c|}
\hline No & Unit Kompetensi & Penjelasan \\
\hline 1. & $\begin{array}{l}\text { Melakukan pekerjaan dengan } \\
\text { mesin bubut }\end{array}$ & $\begin{array}{ll}\text { 1. } & \text { Memahami cara menseting mesin bubut } \\
\text { 2. } & \text { Memahami cara pencekaman benda kerja } \\
\text { 3. } & \text { Memahami cara setting pahat. } \\
\text { 4. } & \text { Mampu memilih jenis pahat yang sesuai dengan jenis } \\
\text { 5. } & \text { Mematerial dan pekerjaan yang dikerjakan. } \\
\text { pemesianan dan merawat sistem pendingin. } \\
\text { 6. } \\
\text { Mampu memilih parameter pemesianan (Kecepatan } \\
\text { spindel, feed, kedalaman pemakanan dll) sesuai dengan } \\
\text { 7. } \\
\text { 8. } \text { Mempu melakukan pembubutan panjang dengan presisi. } \\
\text { 9. } & \text { Mampu melakukan pembubutan tirus } \\
\text { 10. } & \text { Mampu melakukan pembubutan ulir } \\
\text { 11. } & \text { Memahami cara mengerinda pahat bubut }\end{array}$ \\
\hline 2. & $\begin{array}{l}\text { Melakukan pekerjaan dengan } \\
\text { mesin frais }\end{array}$ & $\begin{array}{ll}\text { 1. } & \text { Memahami cara menseting mesin frais } \\
\text { 2. } & \text { Memahami cara pencekaman benda kerja } \\
\text { 3. } & \text { Memahami cara setting pahat. } \\
\text { 4. } & \text { Mampu memilih jenis pahat yang sesuai dengan jenis } \\
& \text { material dan pekerjaan yang dikerjakan. } \\
\text { 5. } & \text { Memahami cara memberi pendingin saat proses } \\
\text { pemesianan dan merawat sistem pendingin. } \\
\text { 6. } \\
\text { Mampu memilih parameter pemesianan (Kecepatan } \\
\text { spindel, feed, kedalaman pemakanan dll) sesuai dengan } \\
\text { jenis dan dimensi meterial yang dikerjakan. } \\
\text { 7. } \\
\text { Mempu melakukan Frais permukaan Mampu melakukan } \\
\text { 8. } \\
\text { 9rais bertingkat } \\
\text { 10. } \\
\text { 12. Mampu melakukan Frais sudut } \\
\text { Memahamiakukan cara mengerinda pahat frais }\end{array}$ \\
\hline 3. & $\begin{array}{l}\text { Melakukan pekerjaan dengan } \\
\text { mesin gerinda }\end{array}$ & $\begin{array}{l}\text { 1. Memilih roda gerinda dan perlengkapannya } \\
\text { 2. Memahami cara pengeoperasian mesin gerinda } \\
\text { 3. Memeriksa komponen-komponen untuk kesesuaian } \\
\text { secara spesifik. }\end{array}$ \\
\hline 4. & $\begin{array}{l}\text { Mengoperasikan mesin CNC } \\
\text { bubut }\end{array}$ & $\begin{array}{ll}\text { 1. } & \text { Memasang fixture/perlengkapan/ alat pemegang } \\
\text { 2. } & \text { Melakukan pemeriksaan awal } \\
\text { 3. } & \text { Melakukan pengaturan mesin NC/CNC (numerical } \\
\text { control/ computer numerical control) } \\
\text { 4. } \\
\text { 5. Mempu mengoperasikan software pemprograman NC } \\
\text { 6. } \\
\text { Mampu meilih jenis pahat dan memsetting pahat di mesin } \\
\text { CNC }\end{array}$ \\
\hline
\end{tabular}




\begin{tabular}{|l|l|ll|}
\hline No & \multicolumn{1}{|c|}{ Unit Kompetensi } & & \multicolumn{1}{c|}{ Penjelasan } \\
\hline 5. & $\begin{array}{l}\text { Mengoperasikan mesin CNC } \\
\text { frais }\end{array}$ & 1. & Memasang fixture/perlengkapan/ alat pemegang \\
& & 2. & Melakukan pemeriksaan awal \\
& & 3. & Melakukan pengaturan mesin NC/CNC (numerical \\
& & control/ computer numerical control) \\
& & 4. & Mampu mengoperasikan software pemprograman NC \\
& 5. & Memahami parameter pemesinan \\
& & 6. & Mampu meilih jenis pahat dan memsetting pahat di mesin \\
& & & CNC \\
\hline
\end{tabular}

Dari hasil wawancara dan diskusi dapat diketahui gap kompetensi inti operator bersama pimpinan bengkel, pimpinan mekanik mesin produksi dengan kompetensi yang dimiliki dan operator senior serta angket yang disebarkan oleh lulusan SMK jurusan Teknik Pemesinan. kepada 30 responden di 3 bengkel pemesinan, Hasil wawancara, diskusi dan kuesioner dapat disajikan seperti pada Gambar 3 berikut ini:
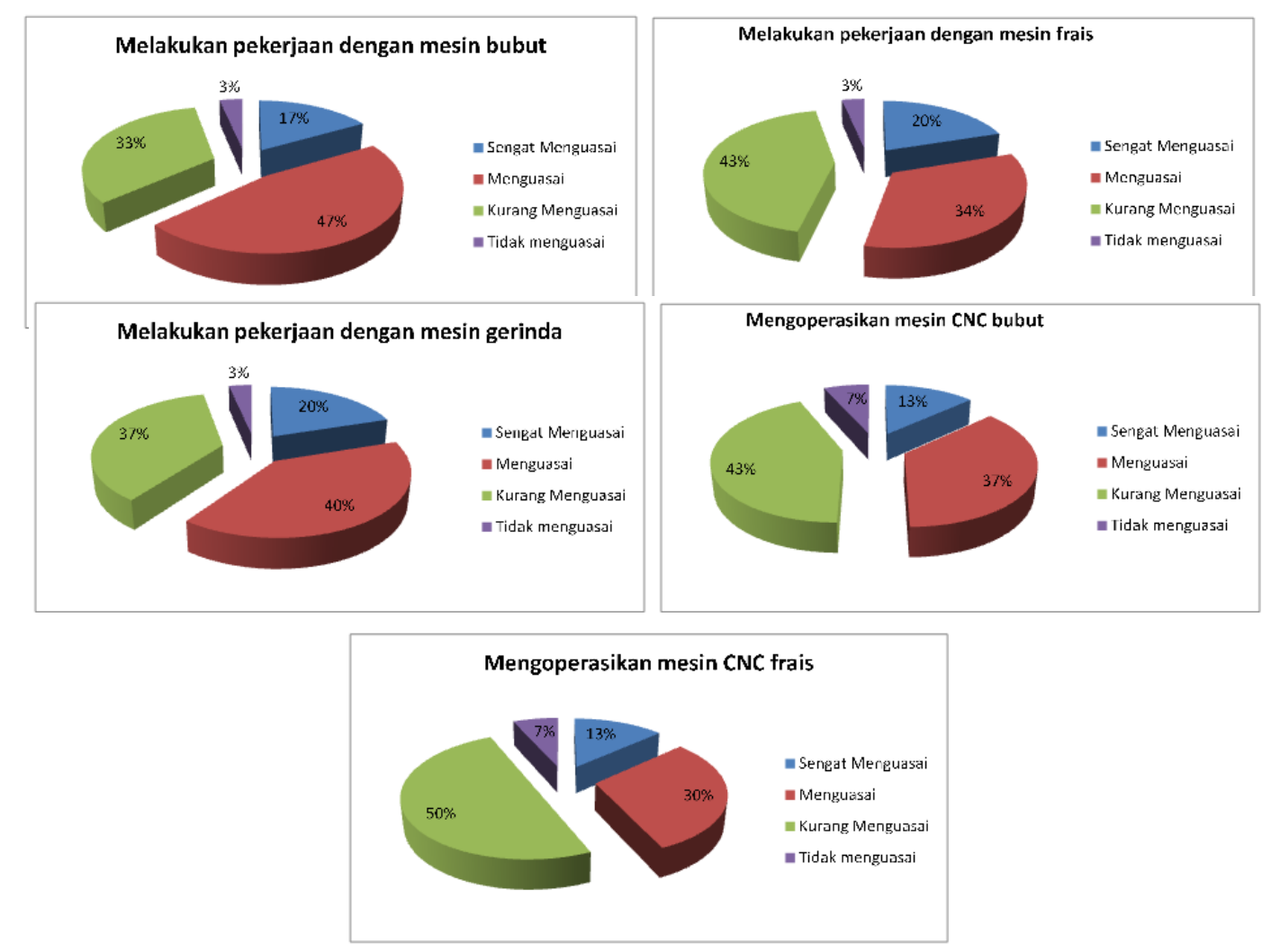

Gambar 3 Grafik penguasaan kompetensi inti profesi operator mesin produksi lulusan SMK jurusan Teknik Pemesinan

Dari data tersebut dapat di ketahui bahwa hampir semua kompetensi yang ada pada kompetensi inti yang disyaratkan oleh profesi operator mesin produksi, Prosentase siswa yang tidak menguasai sama sekali sangatlah kecil yaitu $7 \%$ ke bawah. Sehingga dari sini secara konten atau isi materi pelajaran yang diajarkan pada SMK Jurusan Teknik pemesinan sudah memenuhi tuntutan dalam kompetensi dasar profesi operator mesin produksi. Sehingga yang perlu dicari pemecahannya adalah mengapa dari 5 kompetensi yang ada pada kompetensi dasar, 5 kompetensi kebanyakan siswa SMK masih berada pada level "kurang menguasai", yaitu > $33 \%$.

Sehingga dari peta kompetensi dasar profesi operator mesin produksi ini dapat diketahui dimana letak kekurangan yang dimiliki 
lulusan SMK jurusan Teknik Pemesinan. Selanjutnya yang perlu dilakukan adalah bagaimana mencari solusi dari hasil temuan ini yaitu:

1) Mengapa pada kompetensi inti, lulusan SMK jurusan Teknik pemesinan oleh para pimpinan bengkel, kepala operator dan operator senior dinyatakan dalam kategori kurang menguasai?

2) Bagaimana mengatasi masalah tersebut dalam kaitannya dengan perbaikan pembelajaran yang ada di SMK jurusan Teknik pemesinan?

Kedua masalah tersebut akan diteliti lebih lanjut pada penelitian lanjutan ditahun ke dua dari penelitian ini. Sehingga setelah diperoleh peta kompetensi dan gab yang ada, maka penelitian lanjutannya adalah memecahkan solusi gab yang terjadi berdasarkan peta kompetensi yang telah diperoleh.

\section{Kompetensi penunjang (supporting competency)}

Kompetensi penunjang yaitu kompetensi yang berhubungan dengan prerilaku dan sikap kerja seorang mekanik roda 4. Kompetensi penunjang untuk kompetensi profesi operator mesin produksi, mekanik roda 4 dan roda 2, memiliki kesamaan. Keseamaan ini disebabkan karena merupakan profesi pelayanan yaitu pelayanan service dan perbaikan. Kompetensi penunjang untuk profesi operator mesin produksi adalah seperti pada Tabel 3 dibawah ini:

Tabel 3 Kompetensi penunjang operator mesin produksi

\begin{tabular}{|c|c|c|}
\hline No. & $\begin{array}{c}\text { Unit } \\
\text { Kompetensi }\end{array}$ & penjelasan \\
\hline 1 & $\begin{array}{l}\text { Memahami dan } \\
\text { menerapkan } \\
\text { keselamatan, } \\
\text { kesehatan kerja } \\
\text { dan lingkungan } \\
\text { tempat kerja }\end{array}$ & 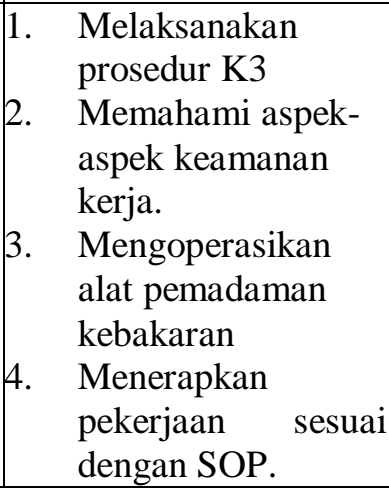 \\
\hline
\end{tabular}

\begin{tabular}{|c|c|c|}
\hline No. & $\begin{array}{c}\text { Unit } \\
\text { Kompetensi }\end{array}$ & penjelasan \\
\hline 2 & $\begin{array}{l}\text { Memahami dan } \\
\text { mampu } \\
\text { merawat alat } \\
\text { kerja dan } \\
\text { lingkungan } \\
\text { kerja }\end{array}$ & $\begin{array}{l}\text { 1. Merawat peralatan } \\
\text { dan perlengkapan } \\
\text { perbaikan di tempat } \\
\text { kerja. } \\
\text { 2. } \\
\text { Menggunakan } \\
\text { peralatan dan } \\
\text { perlengkapan } \\
\text { perbaikan }\end{array}$ \\
\hline 3 & $\begin{array}{l}\text { Kemampuan } \\
\text { dalam } \\
\text { melayani } \\
\text { konsumen }\end{array}$ & 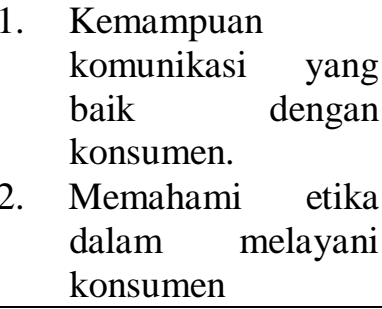 \\
\hline
\end{tabular}

Dari hasil wawancara dan diskusi bersama pimpinan bengkel, pimpinan mekanik dan mekanik senior serta angket yang disebarkan kepada 50 responden di bengkel otomotif roda 4, dapat diketahui gap kompetensi penunjang mekanik otomotif roda 4 dengan kompetensi yang dimiliki oleh lulusan SMK jurusan TKR. Hasil diskusi dan kuesioner dapat disajaikan seperti pada Gambar 4 berikut ini: 


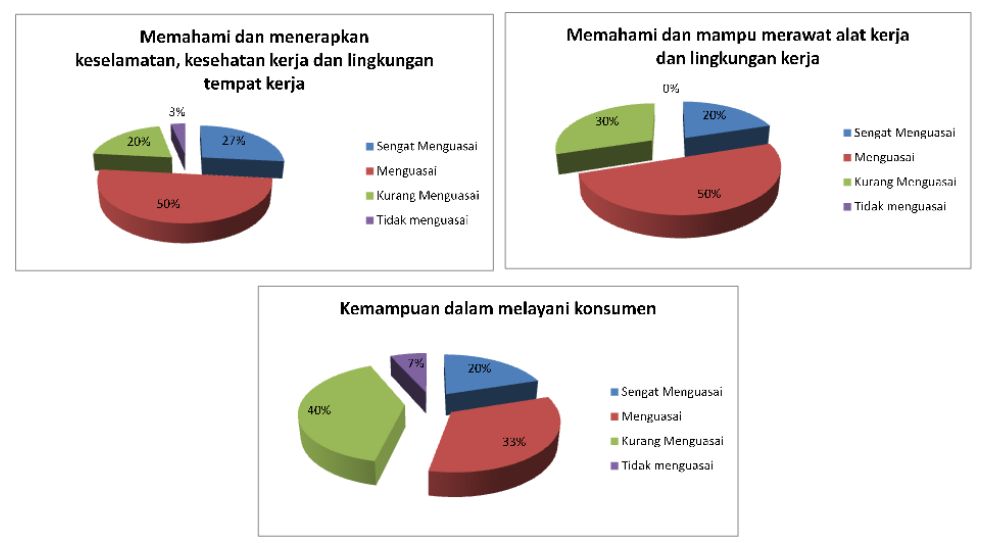

Gambar 4. Grafik penguasaan kompetensi penunjang profesi operator mesin produksi lulusan SMK jurusan Teknik Pemesinan

Kompetensi penunjang yang dimiliki oleh lulusan SMK Jurusan Teknik Pemesinan, menurut pimpinan bengkel, kepala operator mesin dan operator senior di bengkel pemesinan, prosentasi masih kurang menguasi dan tidak menguasainya masih sangat besar, khususnya pada unit kompetensi Memahami dan mampu merawat alat kerja dan lingkungan kerja, serta pada unit kompetensi dalam melayani kosumen.

\section{KESIMPULAN DAN SARAN}

\section{Kesimpulan}

Berdasarkan peta kompetensi operator mesin produksi dapat diketahu bahwa gab kompetensi antara tuntutan dan kompetensi lulusan SMK jurusan Teknik Pemesinan adalah sebagai berikut:

a. Pada kompetensi dasar berdasarkan peta kompetansi dari 4 unit kompetensi yang ada, gab yang paling besar antara kompetensi lulusan dengan permintaan bengkel produksi adalah pada 1) kompetensi membaca gambar teknik dan 2) kompetensi menggunakan perkakas tangan.

b. Dari peta kompetensi dapat di ketahui bahwa hampir semua kompetensi yang ada pada kompetensi inti yang disyaratkan oleh profesi operator mesin produksi, Prosentase siswa yang tidak menguasai sama sekali sangatlah kecil yaitu $7 \%$ ke bawah. Permasalahan pada . Sehingga yang perlu dicari pemecahannya adalah mengapa dari 5 kompetensi yang ada pada kompetensi inti, kompetensi lulusan SMK Jurusan Teknik Pemesinan masih berada pada level "kurang menguasai", yaitu > $33 \%$.

c. Kompetensi penunjang yang dimiliki oleh lulusan SMK Jurusan Teknik Pemesinan, menurut pimpinan bengkel, kepala operator mesin dan operator senior di bengkel pemesinan, prosentasi masih kurang menguasi dan tidak menguasainya masih sangat besar, khususnya pada unit kompetensi Memahami dan mampu merawat alat kerja dan lingkungan kerja, serta pada unit kompetensi dalam melayani kosumen.

\section{Saran}

Dari hasil kajian pada penelitian ini, saran yang dapat penulis berikan untuk tindak lanjut dari penelitian ini adalah:

1. Pada penelitian ini telah berhasil memetakkan dan menemukan gep (perbedaan) kompetensi yang saat ini ada. Sehingga penelitian lanjutan yang dibutuhkan adalah bagaimana $g a b$ tersebut dapat didalami dicari penyebabnya dan dirumuskan alternatif solusi. Sehingga penelitian in dapat bermanfaat untuk memperbaiki kualitas lulusan SMK, khususnya di kota Surakarta.

2. Penelitian ini dilakukan di Surakarta, sehingga diperlukan pembanding untuk penelitian yang serupa dengan lokasi penelitian yang berbeda.

\section{DAFTAR PUSTAKA}

Bennie, K. \& Newstead, K. 1999. Obstacles to implementing a new curriculum. dalam M.J. Smith \& A.S. Jordaan (Eds.) 
Proceedings of the National Subject Didactics Symposium (pp. 150-157). Stellenbosch: University of Stellenbosch

Charles A. Prosser, 1950, Vocational Education in a democracy, Chicago, American Technical Society

Charters \& Jones . 1973. Dikutip oleh Pusat Kurikulum, 2007. Kajian Kebijakan Kurikulum SMK. Jakarta: Badan Penelitian dan Pengembangan, Depdiknas.

Departemen Pendidikan Nasional Republik Indonesia, Undang-undang Republik Indonesia Nomor 20 Tahun 2003 tentang Sistem Pendidikan Nasional, Jakarta 2003.

Departemen Pendidikan Nasional Republik Indonesia, Undang-undang Republik Indonesia Nomor 14 Tahun 2005 tentang Guru dan Dosen, Jakarta 2005.

FauzilahSalleh, NoryatiYaakub, $\&$ ZaharahDzulkifli. 2011. The Influence of Skill Levels on Job Performance of Public Service Employees in Malaysia. http://www.businessjournalz.org/articlep df/bmr004.pdf [diakses 07/09/2012].

Fennema, E. \& Franke, M. 1992. Teachers' knowledge and its impact in: D.A. Grouws (Ed) Handbook of Research on Mathematics Teaching and Learning (New York: Macmillan Publishing).

Hargreaves, D.H. 1995. School Culture, School Effectiveness and School Improvement. School Effectiveness and School Improvement, 6 (1), 23-46

I Gede Sudirtha. 2006. Partisipasi Dunia Usaha Dan Dunia Industri Dalam Pendidikan Kejuruan Studi Pada Pelaksanaan Praktik Industri Siswa SMK Negeri Di Provinsi Bali. Jurnal Pendidikan dan Pengajaran IKIP Negeri Singaraja, No. 2TH. XXXIX April 2006.

Imam Budi. 2004. Persepsi Siswa Kelas III Terhadap Pelaksanaan Pendidikan Sistem Ganda (PSG) Pada SMK Negeri 3 Semarang Tahun Ajaran 2003/2004.
Semarang : Fakultas Teknik Universitas Negeri Semarang.

Kotler, Philip \& Kevin Lane Keller (2006) "Marketing Management" Twelfth Edition, Pearson

Kuswari. (2009). Lulusan SMK Mau ke Mana?. Tersedia pada: http://pendis.depag.go.id/index.php?a=deti lberita\&id=3169 [diakses 15/04/2012].

Mufid. 2009. Tahun ini, pemerintah bangun 200 unit SMK. Tersedia pada: http://www.solopos.com/2009/pendidikan/ tahun-ini-pemerintah-bangun-200-unitsmk-1432 [diakses 03/23/2012].

Nasution, S. 1995. Metode Research. Jakarta: Bumi Aksara

Neuman, W. Lawrence. 2000. Social Research Methods: Qualitative and Quantitative Approaches. Fourth Edition. USA: A Pearson Education Company.

Nolder, R. 1990. Accommodating curriculum change in mathematics: Teachers' dilemmas. dalam Booker, G., Cobb, P. \& de Mendicuti, T.N. (Eds.). Proceedings of the Fourteent Conference of the International Group for the Psychology of Mathematics Education (pp. 167-174). Mexico City, Mexico.

Roe, R.A. (2001). Competencies and competence management. Paper European Congress for W\&O Psychology, Prague, May 1619, 2001.

Sri Utami. 2010. Kemitraan Sekolah Menengah Kejuruan dengan Dunia Usaha dan Dunia Industri melalui Praktik Kerja Industri : Studi Multisitus di SMK Negeri 3 Malang dan SMK Cor Jesu Malang. Tesis. Program Pascasarjana Universitas Negeri Malang.

Stanton Wj. 1992. Manajemen dan Pemasaran.

Erlanggar, Jakarta.

Zeithaml, V.A. and M.J. Bitner. 2003. Services Marketing: Integrating Customer Focus Across the Firm, 3rd edition. Boston: McGraw Hill/Irwtn. 